\title{
THE INTERGENERATIONAL TRANSMISSION OF RELATIONSHIP VIOLENCE
}

by

Marilyn J. Kwong

B.A. (Honours) Simon Fraser University 1997

\author{
A THESIS SUBMITTED IN PARTIAL FULFILL.MENT \\ OF THE REQUIREMENTS FOR THE DEGREE OF \\ MASTER OF ARTS \\ in the Department of Psychology
}

(c) Marilyn J. Kwong 2000

SIMON FRASER UNIVERSITY

July 2000

All rights reserved. This work may not be reproduced in whole or in parts, by photocopy or other means, without the permission of the author. 
National Library

of Canada

Acquisitions and

Bibliographic Services

395 Wellington Street Ottawn ON K1A ONA Canada
Bibliothèque nationale du Canada

\section{Acquisitions of}

senices bibliographiques

395, rue Wellington

Otrawe ON K1A ONA

Canada
The author has granted a nonexclusive licence allowing the National Library of Canada to reproduce, loan, distribute or sell copies of this thesis in microform, paper or electronic formats.

The author retains ownership of the copyright in this thesis. Neither the thesis nor substantial extracts from it may be printed or otherwise reproduced without the author's permission.
L'auteur a accordé une licence non exclusive permettant à la Bibliothèque nationale du Canada de reproduire, prêter, distribuer ou vendre des copies de cette thèse sous la forme de microfiche/film, de reproduction sur papier ou sur format électronique.

L'auteur conserve la propriété du droit d'auteur qui protège cette thèse. Ni la thèse ni des extraits substantiels de celle-ci ne doivent être imprimés ou autrement reproduits sans son autorisation. 


\section{ACKNOWLEDGEMENTS}

I would like to acknowledge Kim Bartholomew for her indispensable guidance during this project and for her mentorship throughout my development as a researcher and psychologist. I would also like to express my gratitude to my mother Georgina and to the memory of my father Edmund for their unwavering encouragement and support. Last, but never least, I must acknowledge my indebtedness to Brian, my lifelong partner, best friend, and personal cheerleader. 


\section{TABLE OF CONTENTS}

Approval Page

Abstract

Acknowledgements

List of Tables

List of Appendixes vii

Introduction 1

$\begin{array}{lr}\text { Method } & 9\end{array}$

Results 15

Discussion $\quad 22$

$\begin{array}{ll}\text { Tables } & 33\end{array}$

$\begin{array}{lr}\text { Notes } & 40\end{array}$

$\begin{array}{ll}\text { References } & 41\end{array}$

$\begin{array}{lr}\text { Appendixes } & 45\end{array}$ 


\section{LIST OF TABLES}

Table I Percentage Endorsing Family of Origin Violence and Ever Relationship Violence $\quad 33$

Table 2 Correlations Among Predictors 34

Table 3 Correlations Among Physical Violence and

Psychological Abuse Dependent Variables $\quad 35$

Table 4 Correlations Among Predictors and

Dependent Variables $\quad 36$

Table $5 \quad$ Regressions for Current Relationship Violence 37

$\begin{array}{lll}\text { Table } 6 & \text { Regressions for Ever Relationship Violence } & 38\end{array}$

Table 7 Regressions for Psychological Abuse 39 


\section{LIST OF APPENDIXES}

Appendix A

Physical Aggression Scale

Appendix B

Psychological Aggression Scale

46 


\section{The Intergenerational Transmission of Relationship Violence}

A great deal of research has focused on testing the proposition that experiencing or witnessing violence in one's family of origin leads to a greater likelihood of experiencing violence in one's future intimate relationships. Indeed, several large-scale studies of representative samples have shown this effect (e.g. Jackson, 1996; Kalmuss, 1984; Straus, Gelles, \& Steinmetz, 1980). For example, Kalmuss (1984) found that people who reported observing parental hitting during childhood had twice the odds of experiencing severe marital aggression than people who did not report any family of origin violence.

These results are often explained from a social learning perspective, which argues that growing up in an abusive family context teaches individuals that the use of aggression is appropriate for dealing with interpersonal conflicts and increases their likelihood of becoming involved in future aggression (Bandura, 1973). Though this is the most general model of social learning, some studies have also tried to investigate more specific modeling hypotheses. For example, a gender-specific model would hypothesize that father-10-mother violence is predictive of men's perpetration and women's victimization in adult relationships. In addition, a rolespecific model would predict that being hit by one's father would result in greater subsequent victimization for either gender since it is the victim role that is being learned.

The findings on these specific social learning models have not been consistent. Some studies have not found any gender-specific effects for the associations between family of origin violence and subsequent relationship violence (e.g., Cappell \& Heiner, 1990; Kalmuss, 1984; MacEwen, 1994). Others have demonstrated gender differences in intergenerational effects although there is great variability across studies in the particular effects found and few, if any, conform to theoretical expectations. Some studies have identified an association between family 
of origin violence and subsequent relationship violence for females but not males (e.g., Follette \& Alexander, 1992; Mihalic \& Elliot), whereas others found an association for males but not females (e.g., O'Keefe, 1997; O'Leary, Malone \& Tyree, 1994). Still other studies have reported associations between family of origin violence and relationship violence for both genders, although the specific patterns differed for men and women. For example, Marshall and Rose (1988) found that parent-to-child family violence predicted both perpetration and victimization for men, but only victimization for women. Doumas, Margolin and John (1994) found that interspousal family violence predicted victimization for women, but perpetration for men. Though these findings show gender variations, the observed differences do not conform to the gender-specific modeling hypothesized by social learning theory. For example, Marshall and Rose (1988) did not find any gender-specific associations between interspousal violence in the family of origin and relationship violence. However, their results partially support role-specific modeling as parent-to-child violence predicted becoming a victim of subsequent relationship violence, regardless of the gender of the violent parent. The study by Doumas et al. (1994) could not test specific gender associations because respondents were asked about abuse between their parents generally, rather than from each parent separately.

The inconsistencies in these findings suggest that, although the intergenerational transmission of violence may be a widely accepted explanation for violence in intimate relationships, the associations between family and relationship violence are far from simple or direct (cf. Widom, 1989). One potential explanation is that it may be more difficult to find effects as research questions become more refined. Finer categories of violence result in smaller group sizes and lower power for the statistical tests. In addition, past studies have often overlooked an important feature of relationship violence, that it is usually both partners in a 
relationship with violence who are being aggressive. Several representative surveys (e.g., Kwong, Bartholomew, \& Dutton, 1999; Magdol, et al., 1997; Morse, 1995; Stets \& Straus, 1990) have shown that the majority of respondents who report experiencing relationship violence, also acknowledge that both partners have engaged in violence. For example, Stets and Straus (1990) found that $49 \%$ of respondents who disclosed violence reported that both spouses had engaged in violence. Similarly, in a sample of young adults (Morse, 1995), over one half of respondents reporting any relationship violence indicated that the violence was bi-directional. Follette and Alexander (1992), one of the few studies of intergenerational violence reviewed that accounted for the bi-directionality of relationship violence, reported very high correlations between respondents' reports of perpetration and receipt (females: $\underline{r}=.77$ and males: $\underline{r}=.75$ ).

The failure to partial out the associations between perpetration and receipt of relationship violence could be related to the lack of consistency in predictions of violence perpetration and victimization. For example, Kalmuss (1984) examined a sex-specific model of marital aggression by limiting a log-linear analysis to respondents who reported only father-to-mother violence and no other type of family of origin violence. However, she did not control for the effect of bi-directional violence in the current marital relationship. Contrary to her prediction that, for both men and women, exposure to father-to-mother violence would increase the likelihood of husband-to-wife violence but not wife-to-husband violence, she found that the likelihood of both types of violence was increased, for both genders. This result may have been due to the bi-directional nature of relationship violence.

There are several additional limitations of previous research on the intergenerational transmission of violence. First, many studies have not defined family of origin violence and relationship violence in ways specific enough to investigate gender- or role-specific modeling 
hypotheses. As mentioned, family violence variables are often combined into one category of "parental violence" (e.g., Doumas et al., 1994; Mihalic \& Elliott, 1997; O’Leary et al., 1994), and it is quite common for researchers to focus solely on violence against women rather than violence against both genders (e.g., Choice, Lamke \& Pittman, 1995; Straus \& Kantor, 1994). Thus, gender- and role-specific modeling cannot be tested.

Second, most representative survey studies have focused on current relationship violence in order to derive incidence rates. However, since the majority of people who have experienced relationship violence indicate that it occurred in the past rather than the present (e.g., Schwartz, 1989; Statistics Canada, 1993; Tjaden \& Thoennes, 2000), limiting analyses to reports of current relationship aggression excludes a large proportion of respondents relevant to the research question. In addition, if the primary research question is concerned with exposure to family of origin violence as a risk factor for relationship aggression, then it makes more sense to look at whether relationship aggression has been experienced ever in one's life rather than just in the 12 months prior to the survey.

Another limitation of past survey studies is that several (Cappell \& Heiner, 1990; Choice et al., 1995; Jackson, 1996; Kalmuss, 1984; Straus \& Kantor, 1994) used data either from the first or second National Family Violence Survey (Straus \& Gelles, 1986; Straus, Gelles, \& Steinmetz, 1980). Studies employing other representative samples would test the generalizability of results. These surveys also excluded participants who were not currently married, or in a "marriage-like" relationship. Excluding people who are single, divorced, or separated may have deflated rates of reported violence since higher rates of relationship violence have been found in samples of dating couples (DeKeseredy \& Schwartz, 1998) and separated or divorced women (Schwartz, 1989) than samples of married couples. 
Psychological abuse is a key aspect of the dynamics of relationship violence yet it has been overlooked in much of the violence research. In a large birth cohort, Moffitt et al. (1997) found correlations between physical violence and psychological abuse of .74 for perpetration and .78 for victimization. The exclusion of psychological abuse in violence research results in the loss of valuable information which could contribute to our understanding of the dynamics of violence. Most people who report physical violence in the past year indicate that it only happened once or twice (Kwong, Bartholomew \& Dutton, 1999). But, that physical aggression may have been an isolated event that occurred during a fight that got out of hand, or it may be an indicator of a chronically emotionally abusive situation that could be escalating into physical violence. Furthermore, there is evidence that emotional abuse may have an equally, if not more, devastating etfect as physical abuse. In one study, $72 \%$ of a sample of battered women reported that emotional abuse had a more severe negative impact on them than physical abuse (Follingstad, Rutledge, Berg, Hause, \& Polek, 1990). A longitudinal study found that emotional abuse was more predictive of marital dissatisfaction and dissolution than physical abuse (Jacobson, Gottman, Gortner, Berns, \& Shortt, 1996). Hence, psychological abuse appears to be an important variable in its own right and its exclusion from much of the past research on relationship violence has seriously limited our understanding of the nature of abuse in intimate relationships and the possible transmission of emotional abuse across generations.

The final limitation of past research relates to measurement issues. Relationship violence has been quantified in different ways across studies, even though most studies employ the same instrument, the Conflict Tactics Scales (Straus, 1979). Many studies have dichotomized violence in order to form violent and non-violent groups (e.g., Cappell \& Heiner, 1990; Kalmuss, 1984). Others have either used raw frequency scores, which sum the total number of violent incidents 
reported (e.g., Follette \& Alexander, 1992; Mihalic \& Elliott, 1997), or weighted frequency scores which are calculated by transforming raw frequency scores into a 6-point scale $(1=\underline{1}$

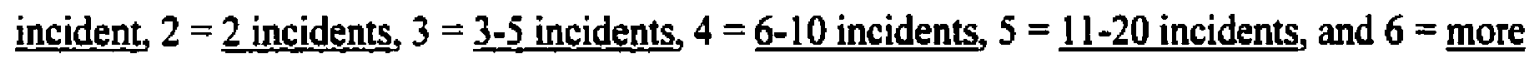
than 20 incidents; e.g., Jackson, 1996; MacEwen, 1992). These variations in measurement may contribute to the inconsistencies in findings.

Traditionally, violence has been quantified dichotomously because the frequency distributions are often so skewed that correlational analyses are inappropriate (Straus, 1979). Consequently, participants are often classified as "violent" if they endorse one or more violent acts and "not violent" if they do not endorse any violent acts. This method results in a heterogeneous violence group that combines people who may have pushed a partner once in their lifetime with people who may have beaten up their partner on a regular basis. Another weakness of this procedure is that the categories are burdened by the unreliability of single items (Moffitt et al., 1997). Some people may be included in the violent category because they reported a single act, whereas others are not included because they forgot about a single act.

Although the frequency of violent acts is an aspect of violence severity, frequency measures are also problematic (Moffitt et al., 1997). In addition to the problem of skewed distributions, people cannot report reliably on how often something has happened, especially if they are reporting about a long time period or if the event is frequent. Also, by summing items into a frequency score, more weight is given to acts that are less serious but more commen, whereas less weight is given to acts that are serious but infrequent. For example, if someone pushed their partner around a number of times, they may obtain a higher violence score than someone who beat up their partner a couple of times. 
These measurement problems highlight the difficulty of trying to capture the severity of violence with dichotomous or frequency measures. With dichotomous measures, should one consider the nature or frequency of the act when establishing a cutoff for severe violence? The CTS defines severe violence as acts that have a greater probability of physical injury (Straus, 1979). However, one could also argue that frequency is an important indicator of severity. These issues also compromise the reliability of the measures and thus the statistical power of the tests.

Variety scores are an altemative measure of violence (Moffitt et al., 1997). They are calculated by summing the number of different violent acts endorsed by participants. For example, if a person reported slapping their partner three times and pushing them five times, they would receive a variety score of two since they endorsed two different acts. There are several advantages to variety scores: (1) the scores are less skewed than frequency scores as each act is only counted once; (2) the endorsement of more acts generally indicates greater severity as the most severe acts are least frequent; (3) variety scores are highly correlated with frequency scores, but more reliable since people can report more accurately on whether something happened than on how many times it happened; and (4) variety scores are less influenced by the unreliability of single items than categorical measures. Research has shown that interpartner agreement about relationship violence is substantially higher with variety scales than with dichotomous measures of violence (Moffitt et al., 1997).

The improved psychometric properties of variety scores may also enable a more accurate assessment of psychological abuse. Researchers have often avoided investigations of psychological abuse because it is even more subjective and thus harder to quantify than physical violence. Establishing a cutoff score for psychological abuse involves a very arbitrary decision. 
For example, when Magdol and colleagues (1997) categorized psychological abuse as the endorsement of any act of verbal aggression in the last 12 months, they obtained incidence rates of $94.6 \%$ for women and $\mathbf{8 5 . 8 \%}$ for men. Though a frequency score would provide information about the severity of emotional abuse, people may find it difficult to report on the frequency of such things as how often a partner controlled their behaviour or criticized them in front of other people.

This study extended previous research in several ways. First, the four forms of family of origin violence (father-to-mother, mother-to-father, father-to-self, and mother-to-self) were kept separate, so that their independent effects could be investigated. Men's and women's reports of relationship abuse were also kept separate so that I could investigate whether gender-specific patterns of abuse held up across both genders' reports of family violence and relationship abuse. Second, the analyses controlled for bi-directional abuse to explore whether any significant effects in the predictions of abuse perpetration and victimization remained. Third, relationship abuse was categorized and analyzed both as current (abuse that occurred in the year prior to the survey) and ever (abuse that occurred at any time in the person's past). Measures of current abuse enabled comparisons to previous research. Measures of ever abuse allowed a more appropriate test of the intergenerational transmission of abuse. Fourth, this study provided another sample to test the generalizability of past research findings and included people who were single, divorced, separated, or widowed, as well as people who were married or cohabiting. Fifth, both physical violence and psychological abuse were included. Finally, relationship violence was measured as both dichotomous variables and continuous variables (frequency scales and variety scores). The enhanced reliability of the variety scores was expected to provide a better test of the intergenerational transmission hypothesis compared to traditional measures of 
aggression (Moffitt et al., 1997). Furthermore, the different measurement methods were compared to see whether the patterns of results were consistent.

Three social learning models of cross-generational violence were explored. A general modeling hypothesis was tested by analyzing whether exposure to any form of family of origin violence was associated with an increased risk of becoming involved in subsequent relationship violence (either as a victim or perpetrator). A role-specific modeling hypothesis was tested by analyzing whether being hit as a teenager by one's parents was more predictive of victimization than perpetration in subsequent relationship violence. A gender-specific modeling hypothesis was assessed by determining whether gender moderated the associations between family of origin violence and subsequent relationship violence. According to this hypothesis, reporting father-to-mother violence should have predicted perpetration for males and victimization for females, whereas mother-to-father violence should have predicted the opposite pattern.

\section{Method}

\section{$\underline{\text { Participants }}$}

The sample consisted of 614 men and 635 women, aged 19 and older, from the City of Vancouver. Participants were contacted via random-digit dialing and completed a 10 to 15 minute telephone survey that assessed physical and emotional abuse in intimate relationships as well as family of origin violence. The survey was conducted in English, Mandarin, and Cantonese. The response rate, calculated as the number of completed interviews $(N=1,249)$ over the number of known eligible respondents $(\mathrm{N}=2,933$ ), was $42.6 \%$. The overall sampling error for the total data at the $90 \%$ confidence level is $2.3 \%$ based on 1,249 interviews.

The survey included respondents with any relationship experience, not only married or cohabiting respondents. The reported marital status of the sample was as follows: married 
(31\%), living with someone (11\%), single and never married (44\%), divorced (7\%), separated (3\%), and widowed (4\%). Of the participants not married or living with someone, $33.4 \%$ were in ongoing romantic or sexual relationships at the time of the survey. The majority of participants identified themselves as heterosexual $(89.9 \%), 4.8 \%$ self-identified as gay or lesbian, $2.9 \%$ selfidentified as bisexual, and $2.3 \%$ did not answer the question. Regarding age levels, $48 \%$ of respondents were between the ages of 19 and $34,39 \%$ were between 35 and 54 , and $13 \%$ were 55 years of age or older. In general, the sample had fairly high levels of education: $21.5 \%$ of respondents had some high school, $60.6 \%$ had some college or university education, and $15.8 \%$ had some post-graduate education. The ethnic breakdown of the sample was as follows: British (28.8\%), other European (23.6\%), Chinese/East Asian (18.3\%), Latin, Central, or South American (2.0\%), and Other (17.2\%). Some respondents did not identify a specific ethnic background $(9.5 \%)$. The distribution of personal income was: less than $\$ 20,000(28.7 \%)$, $\$ 20,000$ to $\$ 29,000(19.4 \%), \$ 30,000$ to $\$ 39,000(15.5 \%), \$ 40,000$ to $\$ 49,000(10.8 \%)$, and over $\$ 50,000(17.4 \%)$. Finally, $8.2 \%$ of the sample either did not know their personal income or declined to answer the question. A comparison with the 1996 Canadian Census data revealed that the current sample was younger (12\% more in the $19-34$ year old category and $13 \%$ less in the 50 or older category), had a higher education (11\% fewer had some high school and $19 \%$ more had some university or college education), and had a higher personal income ( $27 \%$ more had an income greater than $\$ 20,000$ ) than the adult population of the City of Vancouver. Furthermore, despite translating the survey into Cantonese and Mandarin, the Chinese ethnicity was underrepresented by approximately " $10 \% "$ ". 


\section{Measures}

Family of Origin Violence. Two aspects of violence in the family of origin were assessed: aggression between parents, and aggression from parent to teenager. For aggression between parents, respondents were asked about both father-to-mother and mother-to-father aggression. Specifically, respondents were asked to think over their whole childhood and report whether there were ever any occasions when either parent hit or was otherwise physically aggressive towards the other. For aggression between parent and teenager, respondents were asked about both father-to-self and mother-to-self aggression. Specifically, respondents reported on whether, as a teenager, their father or mother hit or was otherwise physically aggressive toward them. Corporal punishment in adolescence has been associated with an increased risk of major adult problem behaviours, including physical abuse of children and husband-to-wife violence (Straus \& Kantor, 1994). Many studies on the intergenerational transmission of violence have used this approach of measuring family of origin violence (e.g., Cappell \& Heiner, 1990; Choice et al., 1995; Jackson, 1996; Kalmuss, 1984; Mihalic \& Elliott, 1997; O'Leary et al., 1994; Straus \& Kantor, 1994). Each of these four variables was scored dichotomously as yes or no.

Physical Aggression Scale. Relationship violence was assessed with a modified version of the Revised Conflict Tactics Scales (CTS2; Straus, Hamby, Boney-McCoy, \& Sugarman, 1996). This measure was comprised of 14 items of physical aggression administered in the following order: pushed or shoved; slapped, thrown something that could hurt; twisted arm or hair; used a knife or gun; punched; hit with something that could hurt; choked; slammed against a wall; beaten up; grabbed or held down in anger; burned or scalded on purpose; kicked; scratched or bitten. Appendix A contains the physical aggression items and wording. 
The procedure for administering the CTS was revised to alleviate redundancy. In previous surveys (e.g., Straus \& Gelles, 1986), respondents were asked how frequently a partner had done a particular act in the past year. If the respondent gave a frequency, this was recorded and the next item was asked. If the respondent said it had not happened, they were then asked if it had ever happened. Each item was asked in this manner for the partner's behaviour then the checklist was repeated with modified wording to ask the respondent about their own behaviour. The weakness of this method was that equal time was spent for relevant and irrelevant items. Thus, the procedure was altered so that respondents were asked to report whether each item had ever happened. Only if respondents endorsed an item were they asked how often this had happened in the last 12 months. Self- and partner-reports were given back to back for each item. This procedure provides four reports of violence: (1) female reports of perpetrated violence, (2) female reports of received violence, (3) male reports of perpetrated violence, and (4) male reports of received violence.

Reported violence was classified into two time periods -- ever and current. The Ever time period includes any violence that is either current or that has happened in the past. Each item was scored dichotomously as Yes (at least one occurrence) or NO (no incident reported). Variety scores were calculated by summing the total number of different violent acts ever inflicted or received. The Current category consists of any incidences of violence experienced in the 12 months prior to the survey. This was scored in three ways: dichotomously, as variety scores, and as raw frequency scores that summed the number of times each item occurred.

Psychological Aggression Scale. Psychological aggression was assessed using 13 items that were derived from the Revised Conflict Tactics Scales (CTS2; Straus et. al, 1996) and the Psychological Maltreatment of Women Inventory (PMWI; Tolman, 1989). Items were chosen to 
include the domains of dominance, isolation, threats of violence, and emotional/verbal abuse. Some items were reworded into more general acts. For example, the item "called a partner fat and ugly" was changed to "called a partner hurtful names." The procedures for administering and scoring these items were the same as those for the physical aggression scale. Appendix B contains the psychological aggression items and wording.

\section{Data Analyses}

Five sets of analyses were conducted: (1) prevalence (ever) rates of relationship violence associated with family of origin violence variables; (2) correlations among the predictors, the dependent variables, and the predictors and dependent variables as a group; (3) multiple regression analyses to examine the independent contributions of the family of origin violence variables to subsequent relationship abuse; (4) moderator analyses to assess the gender-specific social learning model; and (5) regression analyses controlling for the association between the perpetration and receipt of relationship abuse.

Prevalence rates and the correlations were examined for the sample as a whole, as well as separately for men and women. There were no differences in the general pattern of findings for men and women. Therefore, only the correlations for the whole sample are presented.

Analyses on the dichotomously scored dependent variables employed hierarchical logistic regression, a model which, like linear regression, relates one or more predictor variables to a dependent variable (in this case dichotomous). An odds ratio is computed for each predictor which estimates the change in the odds of membership in a particular target group for a one-unit increase in the predictor (Pedhazur, 1997). For example, in Table 2, the odds of perpetrating current relationship violence are 1.72 times greater for people who have experienced mother-toself family violence than for people who have not endorsed this item, after controlling for the 
influence of the other predictors. The Block $\chi^{2}$ is analogous to the $F$-change test in multiple regression which tests the increment in the proportion of variance explained by the variables at their point of entry in a multiple regression analysis (Pedhazur, 1997).

Analyses of the continuous dependent variables (variety scores) employed hierarchical multiple regression. As shown in Tables 5 and 6 , the coefficients used to assess the relationship between the predictors and the continuous dependent variables are standardized beta and change in $R^{2}$. Standardized beta represents the amount of change in the dependent variable per unit change in a particular predictor when all other predictors are statistically controlled (Pedhazur, 1997). Change in $R^{2}$ represents the difference in the proportion of variance in the dependent variable shared by the predictors entered in that block.

Each set of analyses was conducted in a hierarchical format that allowed for statistical control for the effects of gender and age. Some previous surveys have found that rates of female-to-male violence are higher than male-to-female violence (e.g., Bland \& Om, 1986; Grandin \& Lupri, 1997; Magdol, Moffitt, Caspi, Newman, Fagan, \& Silva, 1997). Therefore, it was important to control for this potential effect. Age has also been shown to be negatively associated with relationship violence. Surveys of young adults (e.g., DeKeseredy \& Schwartz, 1998; Magdol et al., 1997) have found higher rates of relationship violence than surveys of adult populations (e.g., Kwong, Bartholomew, \& Dutton, 1999; Straus \& Gelles, 1986). Thus, these variables were entered into the regressions first. In the results section, for each set of analyses, findings for gender and age are reported only if significant. 


\section{Results}

\section{Prevalence Rates of Family of Origin Violence and Ever Relationship Violence}

The first column of Table 1 presents the prevalence rates for the four types of family of origin violence, calculated as proportions of the whole sample. Approximately half of the sample reported never experiencing any family of origin violence, whereas approximately $25 \%$ of the sample endorsed each family violence item. The exception was mother-to-father violence, for which $14 \%$ of the sample reported this act.

The last two columns of Table 1 present the prevalence rates of ever perpetrated and received relationship violence, calculated as proportions within each family violence category. These rates clearly show that each type of family violence is associated with a higher risk for subsequent relationship violence. For example, of respondents who reported never experiencing any family of origin violence, $18.7 \%$ reported perpetrating relationship violence sometime in their past. In contrast, of the respondents reporting that they witnessed father-to-mother violence, $36.3 \%$ reported perpetrating relationship violence sometime in their past. The general pattern of findings is consistent with a general modeling hypothesis but not the gender- or rolespecific modeling hypotheses. That is, each family violence variable was associated with a higher rate of relationship violence, but no particular family violence variable appeared to be more influential than others.

\section{Zero Order Correlations.}

Correlations among Predictors. Table 2 presents the correlations among the hypothesized predictors of relationship violence. The predictors include gender, age, and the four forms of family of origin violence (father-to-mother, mother-to-father, father-to-self, and mother-to-self). Age had a small, negative correlation with the four family violence variables. 
Father-to-mother and mother-to-father violence had a high correlation $(\mathrm{r}=.48)$, as would be expected given previous research on the bi-directionality of violence. Furthermore, there were moderate associations between parents' violence to their spouse, and their violence to their teenager. For example, there was a correlation of .29 between father-to-mother and father-to-self violence, and of .26 between mother-to-father and mother-to-self violence. There was also a moderate correlation between fathers' and mothers' violence to their teenager $(\mathrm{r}=.28)$. Separate correlations for males and females revealed a similar pattern.

Correlations among Relationship Abuse Variables. Table 3 presents correlations among the relationship abuse variables. These variables include measures of ever and current relationship abuse, assessed as both dichotomous and continuous variables. There are a total of eight measures of physical violence. Dichotomous and continuous measures of the same construct were highly correlated $(\underline{r}=.68$ to .83$)$. There were moderately high correlations between reports of perpetrated and received physical violence, ranging from .47 to .66 . Current and ever physical violence were also moderately correlated $(r=.40$ to .44$)$. This was expected since reports of current violence are embedded in reports of ever violence (i.e., respondents were only asked about current if they had already endorsed ever violence).

The lower section of Table 3 presents correlations among the physical violence and psychological abuse variables. The psychological abuse variables were all measured as variety scores and include ever and current abuse. Thus, there are four measures of psychological abuse. The associations among perpetrated and received psychological abuse were high $(\mathrm{r}=.69$ to .77$)$. The correlations among current and ever psychological abuse were moderately high $(r=.45$ to $.49)$, as were the associations among psychological and physical abuse $(r=.42$ to .59$)$. 
Correlations Among Predictors and Relationship Abuse Variables. Table 4 presents correlations among the predictors and relationship abuse variables. In general, these correlations were very small, though most were significant. Gender and physical violence receipt were positively correlated, indicating that males reported significantly more receipt than females. Age was negatively correlated with all of the physical violence variables, indicating that younger respondents tended to report more physical violence than older respondents. The correlations among family of origin violence and subsequent physical violence were small though almost all (46 of 48) were significant due to the large sampling size. The pattern of correlations was not consistent with either gender- or role-specific modeling. For instance, in examining continuous measures of ever physical violence, parent-10-teen violence had approximately the same correlation with perpetration as it did with receipt. Separate correlations by gender did not reveal any gender-specific patterns of association.

The lower section of Table 4 presents the correlations among the predictors and psychological abuse. The pattern of findings was similar to physical violence. However, gender had a small, negative correlation with abuse perpetration, indicating that women reported perpetrating significantly more psychological abuse than men. Age was negatively correlated with all of the psychological abuse variables, indicating that younger respondents tended to report more abuse than older respondents. The correlations among family of origin violence and subsequent psychological abuse were generally small, though almost all (22 of 24) were significant. Again, the pattern of correlations was not consistent with either gender- or rolespecific modeling. 


\section{$\underline{\text { Regression Analvses }}$}

\section{Current Relationship Violence}

Dichotomous Measures of Relationship Violence. Analyses were first done with current relationship violence measured as a dichotomous variable to compare the present findings with those of previous studies. Current relationship violence receipt and perpetration were the dependent variables to be explained by the four family of origin violence variables. Table 5 presents the results. Hierarchical regression analyses were conducted to control for the effects of gender and age. As with the zero order correlations, the results show that the odds ratio for gender is greater than one, indicating that the odds of receiving violence are 1.83 times greater for men than women. The odds ratios for age are smaller than 1 and significant, indicating that each year of age decreases the odds slightly. Family of origin violence added significantly to both models, supporting the general modeling hypothesis. Furthermore, though all of the predictors were generally correlated with the perpetration or receipt of current relationship violence, the only predictor that independently increased the odds of experiencing current relationship violence was mother-to-self violence. Specifically, mother-to-self violence doubled the odds of relationship violence perpetration and receipt after controlling for the effects of the other predictors. Father-to-mother violence was also an independent predictor for relationship violence receipt, but not for perpetration.

Variety Score Measures of Relationship Violence. Parallel analyses were conducted with current relationship violence measured as variety scores. As shown in Table 5, the pattern of results was similar. Gender was positively associated with violence receipt, indicating that men reported significantly more violence receipt than women. Age was negatively associated with violence, indicating that younger respondents tended to report more violence. The family of 
origin violence variables accounted for a small but statistically significant proportion of variance in the prediction $\left(\mathrm{R}^{2}=.01\right.$ to .02$)$. As with the logistic regressions, mother-to-self violence independently predicted current relationship violence perpetration (but not receipt), and fatherto-mother violence independently predicted current relationship violence receipt. Ever relationship violence

Parallel analyses were conducted using both dichotomous and variety score measures of ever relationship violence. Consistent with previous analyses, gender and age were predictors. As presented in Table 6, all analyses show that the family of origin violence variables added significantly to the predictions. However, father-to-mother violence did not independently predicted relationship violence. Across all analyses, father-to-self violence independently predicted ever relationship violence, either as a perpetrator or victim. In addition, mother-tofather violence consistently predicted being a victim, but not a perpetrator, of ever relationship violence. The findings for violence perpetration were not consistent. Furthermore, only the logistic regressions show mother-to-self as independently predicting ever relationship violence. Notably, when compared with current relationship violence, the changes in $R^{2}$ associated with family violence are approximately doubled. Thus, family of origin violence explained a larger proportion of variance when the criterion was ever relationship violence rather than current relationship violence. In summary, the regression analyses were consistent with a general modeling hypothesis of violence, but not a role-specific model.

Moderator Analyses

The Role-Specific Social Learning Model. As discussed, neither the zero-order correlations nor the regression analyses provided support for role-specific modeling of violence. As a further test of this model, interaction terms for the family of origin violence variables were 
entered as a block into the analyses after the original family violence predictors. If a particular combination of family violence is more predictive of one direction of relationship violence (e.g., receipt) than another (e.g., perpetration), certain interaction terms should be significant for certain models. To support a role-specific model, for example, experiencing both father-to-self and mother-to-self violence should be more predictive of relationship violence receipt than perpetration. None of the interaction terms was significant.

The Gender-Specific Social Learning Model. As with role-specific modeling, none of the previous analyses provided support for gender-specific modeling. However, as a further test of this model, interaction terms for family of origin violence by gender were entered into the analyses after the original family violence predictors. If a particular type of family violence is differentially predictive of relationship violence for men or women, these interactions should be significant. For example, if witnessing father-to-mother violence is significantly more predictive of relationship violence perpetration for men than for women, the interaction term between father-to-mother violence and gender should be significant. None of these interaction terms was significant.

Accounting for the associations among violence perpetration and receipt.

The correlations between the perpetration and receipt of violence ranged from .47 to .57 for dichotomous variables and from .61 to .66 for variety scores. To partial out the associations between relationship violence perpetration and receipt, parallel analyses were conducted for all of the previous regressions, controlling for either perpetration or receipt, to test whether any significant effects for family violence remained. For example, if ever relationship violence perpetration was the dependent variable, ever relationship violence receipt was entered as a step in the regression before the family violence variables. For all analyses of relationship violence 
perpetration (current or ever and dichotomous or variety scores), controlling for violence receipt eliminated the significant effects for the family violence variables. Analyses for relationship violence receipt showed that the effects of family violence remained significant. However, the contribution of these variables to the models was reduced substantially. For example, with the continuous dependent variables, the proportion of variance explained by family violence was reduced from $1.5 \%$ to $0.7 \%$ for current relationship violence receipt and from $2.9 \%$ to $0.6 \%$ for ever relationship violence receipt. Thus, the majority of the variance in relationship violence receipt explained by family vioience overlapped with the variance explained by perpetration (and vice versa). Furthermore, there were no consistent patterns in the family violence variables which independently predicted relationship violence receipt, after controlling for perpetration. This suggests that the presence of any type of family violence is a risk factor for subsequent relationship violence receipt but that no specific family violence variable is independently influential.

\section{Psychological Abuse}

Table 7 presents the regression analyses for both current and ever psychological abuse. Hierarchical regression analyses were conducted to control for the effects of gender and age. As with the zero order correlations, the results show that gender was negatively associated with abuse perpetration, indicating that women reported more abuse perpetration than men. Age was negatively associated with abuse, indicating that younger respondents reported more abuse (both inflicted and received) than older respondents. Family of origin violence added significantly to the predictions. Across all analyses, mother-to-self violence independently predicted experiencing abuse, either as a perpetrator or a victim. Mother-to-father and father-to-self violence independently predicted in three of the four models. However, father-to-mother 
violence did not independently predict for any of the analyses. There were no role-specific patterns in the results. For example, parent-to-teen violence independently predicted both perpetrated and received ever abuse.

Compared with the results for relationship violence, the changes in $R^{2}$ for family violence were at least double $\left(\mathrm{R}^{2}=.03\right.$ to .06$)$, indicating that family violence explains a larger proportion of variance for psychological abuse. As with relationship violence, parallel analyses were conducted to control for either perpetration or receipt. Though the effects of the family violence variables remained significant for two of the four analyses, there were no consistent patterns. Furthermore, the contribution of these variables was reduced substantially, with the change in $R^{2}$ ranging from .001 to .01 .

\section{Discussion}

Though past research has provided support for a general social learning model of relationship violence, the findings for more specific social learning models have been inconsistent. One possible explanation for these discrepancies may be variations across studies in the way that relationship violence has been quantified and analyzed. The current study is one of the first projects to include two methods of quantification (dichotomous and continuous) and analysis (logistic regression and multiple regression) in order to assess the consistency of findings across methods. It also extends the literature on relationship violence by addressing some of the methodological limitations of previous studies. For example, most previous studies have not controlled for the bi-directionality of ielationship violence. Furthermore, many studies have combined family violence variables, thereby precluding appropriate tests of gender- or rolespecific models. Finally, the present study included psychological abuse, an important variable 
that often co-occurs with physical abuse and provides valuable information as to the dynamics of violent relationships.

Consistent with previous investigations, the current study found support for a general social leaming model of relationship violence. Across all analyses, exposure to family of origin violence was associated with a greater likelihood of subsequent relationship abuse (perpetrated and received). However, there was no evidence to support either a gender-specific or rolespecific modeling hypothesis. Prevalence rates of ever relationship violence for respondents who reported exposure to any type of family violence were approximately double those of respondents who did not. Zero order correlations revealed similar associations between the family violence variables and the measures of relationship abuse (physical and psychological). These measures included the different methods of quantification (dichotomous and continuous), the two time frames (current and ever), and both directions of experienced aggression (perpetration and receipt). The only exception was the lack of a significant association between mother-to-father violence and current relationship violence perpetration (both dichotomous and continuous measures). This finding may be due to the low endorsement rates of both these variables. The undifferentiated pattern of correlations was evident for the whole sample as well as for men and women as separate samples.

Regression analyses that controlled for the effects of gender and age in the prediction of relationship abuse (both physical and psychological) showed that family violence added a significant proportion of variance to all of the predictions. However, there were no consistent pattems in the specific types of family violence that independently predicted relationship abuse. For example, violence between parents was not more predictive of subsequent relationship violence than parent-to-child violence. Neither was there any evidence that parent-to-child 
violence was more predictive of relationship violence receipt than perpetration (in either the initial regressions or the moderator analyses). Furthermore, in the moderator analyses, the family violence by gender interaction terms were not significant, indicating that respondents were not more likely to model the violent behaviour of their same-sex parent than their oppositesex parent. The overail pattern of findings suggests that all four types of family violence are relatively similar in their influence on relationship abuse (both physical and psychological). Thus, role- and gender-specific models of the intergenerational transmission of relationship violence were not supported.

It also appears that bi-directionality is an integral feature of relationship abuse. Perpetration and receipt of both physical and psychological abuse were highly correlated. Furthermore, for predictions of physical violence, controlling for this association eliminated the significant effects for family violence when predicting relationship violence perpetration. When predicting receipt, the effect for family violence remained significant, though the proportion of variance explained by these variables was reduced substantially. This was most likely due to the higher base rate of victimization. Controlling for bi-directionality in psychological abuse also led to sizeable reductions in the variance explained by family violence, although there were no consistent patterns for the models in which the effects of family violence remained significant. These results indicate that abuse perpetration and receipt tend to coexist to such an extent that it may be difficult to test models that try to predict them separately.

This study also looked at psychological abuse, another important feature of relationship abuse. The correlations between psychological abuse and relationship violence were high. This suggests that abusive relationships are not just about physical violence but, rather, that psychological and physical abuse tend to co-occur. Moreover, these two forms of abuse appear 
to be similarly influenced by family of origin violence. Like physical violence, exposure to family violence was associated with an increased risk of becoming involved in psychologically abusive relationships. In addition, this increased risk appears to be based on general modeling rather than gender- or role-specific modeling.

Direct comparisons of this study with past research are difficult as none of the previous studies reviewed in this paper have both controlled for the association between violence perpetration and receipt and kept the different types of family violence separate in the analyses. However, Cappell and Heiner (1990) did control for the association between violence perpetration and receipt and found that witnessing parental violence was associated with relationship violence receipt but not perpetration. The finding that controlling for the bidirectionality of violence eliminates the significant effects of family violence for perpetration but not receipt is consistent with the current study. Though Cappell and Heiner (1990) concluded that no gender-specific patterns were found in their study, they combined both parents' spousal violence into a general category, thereby precluding an appropriate test of gender-specific modeling.

Two other studies that controlled for the bi-directionality of relationship violence analyzed predictions of violence perpetration but not receipt (Follette \& Alexander, 1992; O'Keefe, 1997). Their findings were not consistent with the present study. O'Keefe (1997) found that, for men only, witnessing interspousal violence was predictive of perpetration. Gender-specific modeling could not be assessed since father-to-mother and mother-to-father violence were collapsed into one category. In contrast, Follette and Alexander (1992) found that, for women only, father-to-self violence was predictive of perpetration. This finding is not consistent with either a gender-specific or role-specific modelling hypothesis. 
Although there were no consistent gender-specific patterns in the associations between family violence and relationship abuse in the current study, it appeared that father-to-mother violence was the least predictive family violence variable (it was an independent predictor in only 2 of 12 analyses) and mother-to-self was the most predictive family violence variable (it was an independent predictor in 9 of 12 analyses). The independent predictions for mother-toself violence, however, were not consistent with the role-specific modeling of violence: motherto-self violence predicted both perpetration and receipt of relationship violence and psychological abuse. It is difficult to speculate on the reasons for mother-to-self violence being a more common independent predictor of relationship abuse. Although mother-to-self violence had a prevalence rate similar to other types of family violence, it may have been more severe or frequent than other types of family violence in the families in which it did occur. Consequently, it may have been a more salient experience for respondents and thus more predictive of subsequent relationship violence than other types of family violence. An alternative explanation for this finding is that the mother-child relationship may be more key in relationship development than the father-child relationship. In this case, the mother's aggression would also be more salient for the individual. Because this finding is not consistent with the social learning models or previous research, however, replication is essential before any definitive interpretations and conclusions can be made.

One of the limitations of the current study is the measurement of family of origin violence. Unfortunately, these variables were only measured dichotomously, precluding analyses of the severity or frequency of these acts. This method of quantifying family violence was not as sensitive a measure as that used for quantifying relationship violence. Continuous measures of family violence would have been more appropriate. Another limitation of our 
measure of family violence is that the question posed to respondents asked whether there were ever any occasions when either parent hit or was otherwise physically aggressive towards the other. It would have been more precise to ask whether the respondent had witnessed these acts rather than just whether there were any incidents. It is possible that some respondents were reporting on violence between their parents that they believed to have happened, rather than what they actually know or witnessed to have happened. Furthermore, our measure of family violence did not assess psychological abuse.

Another potential limitation in the measurement of family violence is that these measures rely on retrospective reports. Reports of the distant past are vulnerable to inaccuracies and biases. Furthermore, individuals with current problems may be more sensitive to past problems and, thus, systematically report more family violence than individuals with similar family backgrounds but more satisfactory current relationships. Finally, individuals who have acknowledged relationship violence may be more likely to also report family violence as a way of justifying their behaviour (either consciously or unconsciously).

Though it is difficult to address the limitations of retrospective reports, longitudinal studies provide a way of controlling for the possible contamination of simultaneous reporting of violence in the family of origin and the current relationship by collecting the information in separate time periods (e.g., MacEwen \& Barling, 1988). Unfortunately, this is not an option in cross-sectional research. However, it would still be possible to obtain a more sensitive measure of family violence by obtaining subjective frequency reports of various types of acts, ranging from minor to severe. For example, Marshall and Rose (1988) had respondents rate several family violence acts on a scale from never (1) to very ofien (5). This measurement scale is able to capture the subjective frequency of various acts while acknowledging the inability of 
respondents to report accurately on how many times something may have happened in the distant past.

The issue of bias in reporting is an especially important one for violence research. There are many potential motives for inaccurate reporting. For example, perpetrators may try to deny or minimize their violent acts, and victims may underreport out of fear of reprisal or feelings of shame (see Moffitt et al., 1997, for a more thorough discussion of potential reporting biases). Archer (1999) conducted a meta-analytic study of reliability in reporting relationship violence, as measured by the CTS. Not surprisingly, he found that both genders tend to underreport their own aggression. Though meta-analysis provides important information about the general biases found in violence reports, it is impossible to determine which biases, if any, exist in a particular study. However, analyses on agreement of violence reports in this study indicated that, for female-to-male violence, men's reports of victimization were higher than women's reports of perpetration (Kwong \& Bartholomew, 1998). Men and women did not significantly differ in their reports of male-to-female violence. There are several potential explanations for this finding: (1) men may be overreporting their victimization, (2) women may be underreporting their perpetration, (3) both biases may be operating to a certain degree, and (4) this may be accurate (i.e., the male respondents may have received more violence than the female respondents have perpetrated) because of lack of equivalence between the male and female subsamples.

The last point raises the issue of selection biases in surveys. It is possible that the most abused or violent individuals are underrepresented. If this were the case in the present survey, then the range of violence reported would be restricted, reducing the associations between the variables. However, the rates of ever relationship violence found in this study were higher than 
those found in other Canadian surveys (e.g., Bland \& Orn, 1986; Statistics Canada, 1993). It is also possible that the typical sampling methodology of using random digit dialing may have systematically excluded the most assaultive or victimized individuals in a gender-specific way. Some battered women would be inaccessible, either because they do not have access to their phone or because they are in transition homes. Some highly abusive men could be incarcerated, making them inaccessible for this survey. This may have resulted in an underestimate of severe male-to-female abuse, thereby making gender-specific associations more difficult to detect.

The community sample collected for this study was not representative of the general population. The respondents were younger, more educated, and had higher incomes than the general population. The Chinese population was also underrepresented. Therefore, generalization of these findings must be done with caution. Furthermore, the response rate of the current survey (43\%) was moderately low. Although there appears to be no relation between response rates and violence rates, the possibility of systematic biases in participation remains.

Almost all previous research on the intergenerational transmission of violence has focused on individuals as the unit of analysis, since only one partner of the violent couple is interviewed. However, to study behaviour in couples, it is important to look at both partners. Family relations theory proposes that intimate relationships are mutual constructions which create a dynamic that transcends the individuals (e.g., Byng-Hall, 1999). Therefore, it is possible that the interaction of both partners' family backgrounds would be more strongly predictive of subsequent relationship violence than only one partner's background. Based on social learning theory, it could be expected that, compared to people with violent family backgrounds, people from non-violent families are more likely to have developed positive models about relationships and effective ways of dealing with conflict. They are probably also less likely to tolerate abusive 
behaviour from a partner. Therefore, it is possible that a non-violent family background could act as a protective factor against experiencing future relationship violence. Thus, violence may be much less likely to arise in couples in which only one partner has a background of family violence compared to couples in which both partners have violence in their family background. Future research should use couple data to investigate the intergenerational transmission of violence.

Future research should also investigate other developmental variables that may contribute to abuse potential. Notably, biological and genetic contributors to violence have generally been overlooked in the family violence literature (DiLalla \& Gottesman, 1991). Yet, studies have demonstrated a clear link between genetic and physiological factors and violent crime (DiLalla \& Gottesman, 1991). With respect to the current study, the observed associations between family violence and subsequent relationship violence could be explained by genetic factors. As DiLalla and Gottesman (1991) have pointed out, the integration of the social and biological literatures may provide researchers with greater insight into this complex problem.

An important contribution of this study was that it compared different methods of quantifying and analyzing associations between family violence and subsequent relationship violence. It also tested an alternative method of measuring violence, variety scores, that have been shown to be more reliable than frequency scales. Initial analyses revealed that variety scores did explain a larger proportion of variance than frequency scales, so subsequent analyses using continuous measures were restricted to variety scores. Overall, analyses for dichotomous and continuous variables yielded consistent findings. Thus, it is unlikely that inconsistencies in past findings are due to differences in measurement methods. The differences that occurred were most likely due to random error, as there were no clear patterns in these discrepancies. 
Another contribution of this study is the inclusion of the ever time frame for relationship violence. As mentioned, most individuals who have experienced relationship violence and/or psychological abuse experienced it in the past. It therefore makes more theoretical sense to investigate the intergenerational transmission of violence by looking at individuals' complete history of relationship aggression, not just the 12 months prior to the survey. If an individual learns the use of aggression from their family of origin, one would expect their past behaviour to be a more reliable indicator of their aggressive tendencies than only their current behaviour. Although there were no clear patterns in the specific family violence variables that independently predicted relationship abuse, these variables explained a larger proportion of variance in the predictions of ever abuse than current abuse. Furthermore, family violence had consistently larger correlations with ever relationship abuse than current relationship abuse (although the differences between these correlations were not significant). These findings provide some evidence for a stronger association of family violence with past rather than current abuse.

Two of the most important contributions of this study are the systematic tests of the three social learning models and the inclusion of psychological abuse. By keeping all family violence variables separate, the current study could test gender- and role-specific models that would be predicted by social learning theory. The results support previous findings that the intergenerational transmission of relationship violence follows a general modeling principle rather than anything gender- or role-specific. Though many previous studies have claimed to demonstrate "gender-specific" effects, these findings have generally not been consistent with predictions based on social learning theory. This was often due to combining both parents' violence into one variable. Furthermore, accounting for the bi-directionality of relationship violence in this study demonstrated that trying to predict violence perpetration and victimization 
separately may be difficult. The current findings also extend previous work by showing that family violence predicts psychological as well as physical abuse in intimate relationships. Like physical violence, it is a bi-directional phenomenon and appears to be associated with family violence in a general, rather than role- or gender-specific, way.

Given the results of the present and previous studies, it appears that abusive behaviours may be transmitted across generations in a general way. Furthermore, efforts to delineate more specific connections between the abusive behaviours of parents and their offspring may be difficult because of the high reciprocity of both physical and psychological abuse. Finally, although the associations between family violence and subsequent relationship abuse are consistent, they are not very strong (Kalmuss, 1984). Social learning theory can only explain a small part of a very complex picture. Future research could make greater contributions to our understanding of the intergenerational transmission of violence by shifting more attention to a couple level of analysis, and by looking more broadly at the developmental antecedents of relationship violence. 
Table 1

Percentage Endorsing Family of Origin Violence and Ever Relationship Violence

\begin{tabular}{|c|c|c|c|}
\hline \multirow[b]{2}{*}{ Family of Origin Violence ${ }^{l}$} & \multirow[b]{2}{*}{$\%$ of whole sample } & \multicolumn{2}{|c|}{ Ever Relationship Violence } \\
\hline & & $\begin{array}{c}\text { Perpetration } \\
(\%)\end{array}$ & $\begin{array}{c}\text { Receipt } \\
\text { (\%) }\end{array}$ \\
\hline None & 50.4 & 18.7 & 22.5 \\
\hline Father-to-Mother & 23.0 & 36.3 & 41.8 \\
\hline Mother-to-Father & 13.9 & 40.6 & 48.5 \\
\hline Father-to-Self & 28.5 & 36.7 & 45.2 \\
\hline Mother-to-Self & 24.1 & 39.4 & 48.4 \\
\hline
\end{tabular}

Note: proportions calculated as a percentage within a particular category of family of origin violence

' $\mathrm{N}$ 's varied from 1,187 to 1,212 because of missing data 
Table 2

Correlations Among Predictors

\begin{tabular}{|c|c|c|c|c|c|c|}
\hline \multirow[b]{2}{*}{ Predictors } & \multicolumn{5}{|c|}{ Predictors } & \multirow[b]{2}{*}{ Mother-to-Self } \\
\hline & Gender & Age & Father-to-mother & Mother-to-father & Father-to-self & \\
\hline Gender & $\cdots$ & & & & & \\
\hline Age & -.032 & --- & & & & \\
\hline Father-to-mother & -.022 & -.053 & ---- & & & \\
\hline Mother-to-father & $.075^{*}$ & $-.090^{* *}$ & $.479^{* *}$ & $\cdots$ & & \\
\hline Father-to-self & .049 & $-.058^{*}$ & $.287^{* *}$ & $.123^{* *}$ & --- & \\
\hline Mother-to-self & .031 & $-.096 * *$ & $.164^{* *}$ & $.255^{* *}$ & $.284^{* *}$ & --- \\
\hline
\end{tabular}

Note: Listwise $\mathrm{N}=1,165$

${ }^{*} p<.05{ }^{* *} p<.01$ 
Table 3

Correlations Among Physical Violence and Psychological Abuse Dependent Variables

\begin{tabular}{|c|c|c|c|c|c|c|c|c|c|c|c|c|}
\hline \multirow[b]{2}{*}{$\begin{array}{l}\text { Dependent } \\
\text { Variables }\end{array}$} & \multicolumn{4}{|c|}{ Dichotomnus Violence Variables . } & \multicolumn{4}{|c|}{ Continuous Violence Variables } & \multicolumn{4}{|c|}{ Psychological Abusic Variables } \\
\hline & $\begin{array}{l}\text { Ever } \\
\text { Perp }\end{array}$ & $\begin{array}{l}\text { Ever } \\
\text { Receipt }\end{array}$ & $\begin{array}{l}\text { Current } \\
\text { Perp }\end{array}$ & $\begin{array}{l}\text { Current } \\
\text { Receipt }\end{array}$ & $\begin{array}{l}\text { Ever } \\
\text { Perp }\end{array}$ & $\begin{array}{l}\text { Ever } \\
\text { Receipt }\end{array}$ & $\begin{array}{l}\text { Current } \\
\text { Perp }\end{array}$ & $\begin{array}{l}\text { Current } \\
\text { Receipt }\end{array}$ & $\begin{array}{l}\text { Ever } \\
\text { Perp }\end{array}$ & $\begin{array}{l}\text { Ever } \\
\text { Receipt }\end{array}$ & $\begin{array}{l}\text { Current } \\
\text { Perp }\end{array}$ & $\begin{array}{l}\text { Current } \\
\text { Receipt }\end{array}$ \\
\hline \multicolumn{13}{|c|}{$\begin{array}{l}\text { Dichotomous Violence } \\
\text { Variables: }\end{array}$} \\
\hline Ever Perp & $\cdots$ & & & & & & & & & & & \\
\hline Ever Rrceip! & $.57 * *$ & $\cdots$ & & & & & & & & & & \\
\hline Curr Perp & $.44^{* *}$ & $.19 * *$ & $\cdots$ & & & & & & & & & \\
\hline Curr Rrceipt & $.28 * *$ & $.43^{\circ *}$ & $.47^{* *}$ & --- & & & & & & & & \\
\hline \multicolumn{13}{|l|}{$\begin{array}{l}\text { Continuous Violence } \\
\text { Variables: }\end{array}$} \\
\hline Ever Perp Total & $.74^{* *}$ & $.52 * *$ & $.33 * *$ & $.24 * 0$ & $\cdots$ & & & & & & & \\
\hline Ever Rtceip1 Total & $.52 *$ & $.71 *$ & $.19 *$ & $.33 * *$ & $.66 * *$ & $\cdots$ & & & & & & \\
\hline Curr Perp Total & $.36 * *$ & $.21 *$ & $.81+0$ & $.49 * *$ & $.41 * *$ & $.26^{* *}$ & $\cdots$ & & & & & \\
\hline Curr Receipt Total & $.22 * *$ & $.32 * 0$ & $.43^{\bullet \cdots}$ & $.73 * *$ & $.26^{* *}$ & $.40 * \cdots$ & $.61^{\circ}$ & $\ldots$ & & & & \\
\hline \multicolumn{13}{|l|}{$\begin{array}{l}\text { Psychological } \\
\text { Abuse Variables: }\end{array}$} \\
\hline Ever Perp & $.53 * *$ & $.46^{* *}$ & $.21 * *$ & $.18 * *$ & $.54 * 0$ & $47 * *$ & $.23 * *$ & $.16 * *$ & --- & & & \\
\hline Ever Receipt & $.45 * *$ & $.58 * *$ & $.15^{* *}$ & $.25 * *$ & $.44^{* *}$ & $.59 *$ & $.17^{* *}$ & $.23 * *$ & $.69^{* *}$ & --- & & \\
\hline Current Perp & $.37 * *$ & $.25 * *$ & $.42 * *$ & $.38 * *$ & $.37 * \bullet$ & $.26^{* *}$ & $.42 * *$ & $.33 * 4$ & $.49 * *$ & $.26 * *$ & -- & \\
\hline Current Receipt & $.35 * *$ & $.36+*$ & $.39 * *$ & $.51 * *$ & $.31 * *$ & $.33 * *$ & $.39^{* *}$ & $.46^{\circ *}$ & $.37^{* *}$ & $.45^{* *}$ & $.77 * 4$ & $\ldots$ \\
\hline
\end{tabular}


Table 4

Correlations Among Predictors and Dependent Variables

\begin{tabular}{|c|c|c|c|c|c|c|}
\hline \multirow[b]{2}{*}{$\begin{array}{l}\text { Dependent } \\
\text { Variables }\end{array}$} & \multicolumn{5}{|c|}{ Predictors } & \multirow[b]{2}{*}{$\begin{array}{l}\text { Mother } \\
\text { to-Self }\end{array}$} \\
\hline & Gender & Age & $\begin{array}{l}\text { Father- } \\
\text { to-Mother }\end{array}$ & $\begin{array}{l}\text { Mother- } \\
\text { to-Father }\end{array}$ & $\begin{array}{l}\text { Father- } \\
\text { to-Self }\end{array}$ & \\
\hline \multicolumn{7}{|l|}{$\begin{array}{l}\text { Dichotomous Violence } \\
\text { Variables: }\end{array}$} \\
\hline Ever Perpetration & -.03 & $-.10^{* *}$ & $.11 * *$ & $.12 * *$ & $.12 * *$ & $.16^{* *}$ \\
\hline Ever Receipt & $.07^{*}$ & $-.15 * *$ & $.10^{* *}$ & $.13^{* *}$ & $.15^{* *}$ & $.19 * *$ \\
\hline Current Perpetration & -.05 & $-.14 * *$ & $.07^{*}$ & .03 & $.08 *$ & $.11 * *$ \\
\hline Current Receipt & $.08 * *$ & $-.17^{* *}$ & $.12 * *$ & $.13^{* *}$ & $.07^{*}$ & $.14 * *$ \\
\hline \multicolumn{7}{|l|}{$\begin{array}{l}\text { Continuous Violence } \\
\text { Variables: }\end{array}$} \\
\hline Ever Perpetration Total & -.04 & $-.08 * *$ & $.10 * *$ & $.11^{* *}$ & $.13^{* *}$ & $.10^{* *}$ \\
\hline Ever Receipt Total & .00 & $-.09 * *$ & $.07^{*}$ & $.12 *$ & $.13 * *$ & $.11^{* *}$ \\
\hline Current Perpetration Total & -.01 & $-.12 * *$ & $.07^{*}$ & .03 & $.07^{*}$ & $.09 * 4$ \\
\hline Current Receipt Total & $.08 * n$ & $-.11 * *$ & $.12 * *$ & $.10^{* *}$ & $.07^{*}$ & $.06^{*}$ \\
\hline \multicolumn{7}{|l|}{$\begin{array}{l}\text { Psychological } \\
\text { Abuse Variables: }\end{array}$} \\
\hline Ever Perpetration & $-.12 * *$ & $-.10^{* *}$ & $.15 * *$ & $.18 * *$ & $.17^{\star *}$ & $.17 * *$ \\
\hline Ever Receipt &. .04 & $-.10^{* *}$ & $.13^{* *}$ & $.15^{* *}$ & $.15 * *$ & $.17 * *$ \\
\hline Current Perpetration & $-.14 * *$ & $-.27 * *$ & $.10 * *$ & $.11 * *$ & $.10^{* *}$ & $.15^{* *}$ \\
\hline Current Receipt & .00 & $-.22 * *$ & $.10^{* *}$ & $.12 * *$ & $.14^{* *}$ & $.17 * *$ \\
\hline
\end{tabular}

Note: Listwise $\mathrm{N}=1,165$

${ }^{*} p<.05{ }^{* *} p<.01$ 


\section{Table 5}

Regressions for Current Relationship Violence

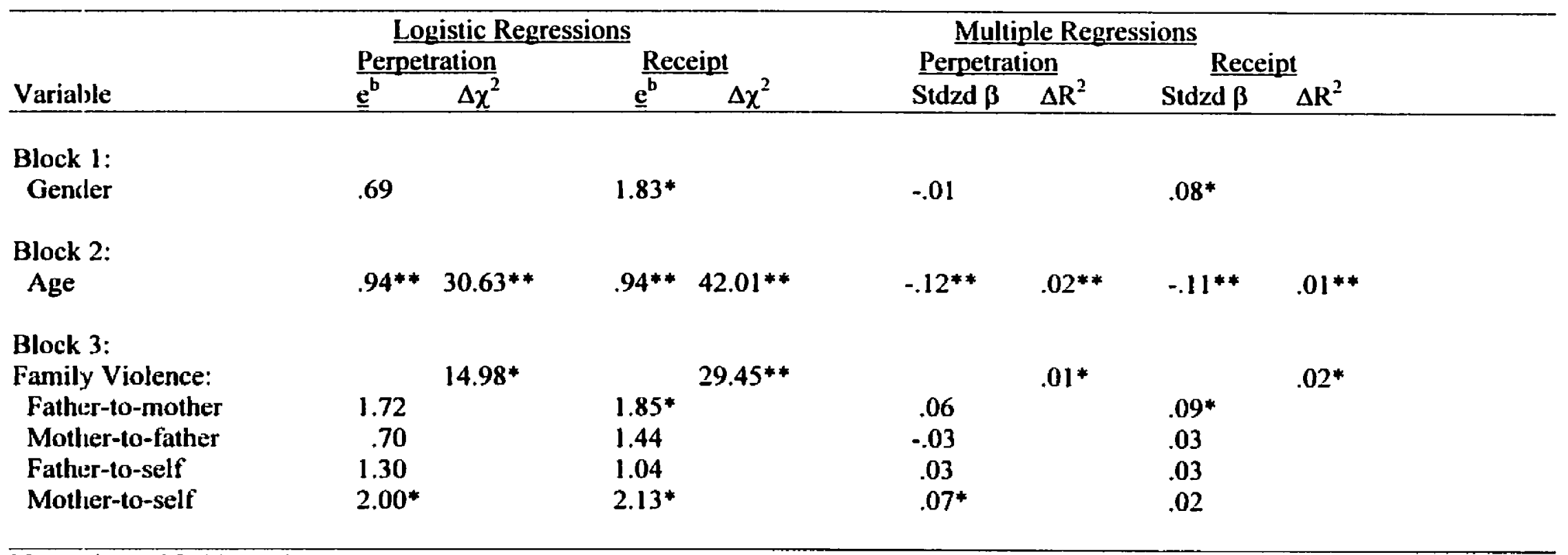

Note: ${ }^{*} p<.05{ }^{* *} p<.001$

Logistic Regressions: DV is perpetration or receipt of relationship violence scored dichotomously. Multiple Regressions: DV is perpetration or receipt of relationship violence scored continuously as variety scores 
Table 6

Regressions for Ever Relationship Violence

\begin{tabular}{|c|c|c|c|c|c|c|c|c|}
\hline \multirow[b]{3}{*}{ Variable } & \multicolumn{4}{|c|}{ Logistic Regressions } & \multicolumn{4}{|c|}{ Multiple Regressions } \\
\hline & \multicolumn{2}{|c|}{ Perpetration } & \multicolumn{2}{|c|}{ Receipt } & \multicolumn{2}{|c|}{ Perpetration } & \multicolumn{2}{|c|}{ Receipt } \\
\hline & $\underline{e}^{b}$ & $\Delta \chi^{2}$ & $\underline{e}^{b}$ & $\Delta \chi^{2}$ & Stdzd $\beta$ & $\Delta \mathrm{R}^{2}$ & Stdzd $\beta$ & $\Delta \mathbf{R}^{2}$ \\
\hline \multicolumn{9}{|l|}{ Block 1: } \\
\hline Gender & .86 & & $1.32^{*}$ & & -.04 & & -.00 & \\
\hline \multicolumn{9}{|l|}{ Block 2: } \\
\hline Age & $.98 * *$ & $13.51^{* *}$ & $.98 * *$ & $25.68 * *$ & $-.08 *$ & $.01^{*}$ & $-.09 *$ & $.01^{*}$ \\
\hline \multicolumn{9}{|l|}{ Block 3: } \\
\hline Family Violence: & & $37.82 * *$ & & $50.45^{* *}$ & & $.03 * *$ & & $.03^{* *}$ \\
\hline Father-to-mother & 1.25 & & 1.07 & & .03 & & -.02 & \\
\hline Mother-to-father & 1.39 & & $1.50^{*}$ & & $.07^{*}$ & & $.10^{*}$ & \\
\hline Father-to-self & $1.38 *$ & & $1.57^{*}$ & & $.10^{*}$ & & $.11 * *$ & \\
\hline Mother-to-self & $1.72^{*}$ & & $1.84^{* *}$ & & .05 & & .05 & \\
\hline
\end{tabular}

Note: ${ }^{*} p<.05{ }^{* *} p<.001$

Logistic Regressions: DV is perpetration or receipt of relationship violence scored dichotomously. Multiple Regressions: DV is perpetration or receipt of relationship violence scored continuously as variety scores 
Table 7

Regressions For Psychological Abuse

\begin{tabular}{|c|c|c|c|c|c|c|c|c|}
\hline \multirow[b]{3}{*}{ Variable } & \multicolumn{4}{|c|}{ Current Psychological Abuse } & \multicolumn{4}{|c|}{ Ever Psychological Abuse } \\
\hline & \multicolumn{2}{|c|}{ Perpetration } & \multicolumn{2}{|c|}{ Receipt } & \multicolumn{2}{|c|}{ Perpetration } & \multicolumn{2}{|c|}{ Recejpt } \\
\hline & Sidzd $\beta$ & $\Delta \mathbf{R}^{2}$ & Stdzd $\beta$ & $\Delta \mathrm{R}^{2}$ & Stdzd $\beta$ & $\Delta \mathbf{R}^{2}$ & Stdzd $\beta$ & $\Delta \mathbf{R}^{2}$ \\
\hline \multicolumn{9}{|l|}{ Block 1: } \\
\hline Gender & $-.14^{* *}$ & & .00 & & $-.12 * *$ & & -.04 & \\
\hline \multicolumn{9}{|l|}{ Block 2: } \\
\hline Age & $-.28 * *$ & $.08 * *$ & $-.22^{*}$ & $.05^{* *}$ & $-.11 * *$ & $.01^{* *}$ & $-.10^{* *}$ & $.01 * *$ \\
\hline \multicolumn{9}{|l|}{ Block 3: } \\
\hline Family Violence: & & $.03 * \bullet$ & & $.03 * *$ & & $.06^{* *}$ & & $.05^{* *}$ \\
\hline Father-to-mother & .01 & & .01 & & .03 & & .03 & \\
\hline Mother-to-father & $.07^{*}$ & & .06 & & $.13 * *$ & & $.10^{*}$ & \\
\hline Father-to-self & .05 & & $.09^{*}$ & & $.12^{* *}$ & & $.10^{* *}$ & \\
\hline Mother-to-self & $.10^{* *}$ & & $.11^{* *}$ & & $.09^{*}$ & & $.11^{* *}$ & \\
\hline
\end{tabular}

Note: ${ }^{*} p<.05{ }^{* *} p<.001$ 
Notes

' Thirty-seven of the respondents who reported that they had no previous relationship experience were excluded from all analyses.

${ }^{2}$ Another approach to analyzing count data is the negative binomial regression model, which more accurately captures the features of this data (Gardner, Mulvey, \& Shaw, 1995). However, this model has not been shown to substantially affect the associations between the predictors and dependent variable, and its main advantage is for predicting the behavior of an individual. Therefore, it was not used for the current study.

${ }^{3}$ Analyses were also done with raw frequencies of relationship violence recoded to a 0 to 6 scale. The pattern of results was similar but the $R^{2}$ change coefficients were smaller. Therefore, only variety scores are presented here.

${ }^{4}$ Rates were also analyzed separately by gender, but no gender differences were found.

${ }^{5}$ Females were coded 0 ; males were coded 1. 


\section{References}

Archer, J. (1999). Assessment of the reliability of the Conflict Tactics Scales: A metaanalytic review. Journal of Interpersonal Violence, 14, 1263-1289.

Bandura, A. (1973). Aggression: A social learning analysis. Englewood Cliffs, NJ: Prentice-Hall.

Bland, R., \& Orn, H. (1986). Family violence and psychiatric disorder. Canadian Journal of Psychiatry, 1, 129-137.

Byng-Hall, J. (1999). Family and couple therapy: Toward greater security. In J. Cassidy \& P. R. Shaver (Eds.), Handbook of Attachment: Theory, Research, and Clinical Applications (pp. 625-645). New York: Guilford Press.

Cappell, C., \& Heiner, R. B. (1990). The intergenerational transmission of family aggression. Joumal of Family Violence, 5, 135 - 152.

Choice, P., Lamke, L. K., \& Pittmann, J. F. (1995). Conflict resolution strategies and marital distress as mediating factors in the link between witnessing interparental violence and wife battering. Violence and Victims, 10, $107-119$.

DeKeseredy, W., \& Schwartz, M. D. (1998). Woman abuse on campus: Results from the Canadian National Survey. Thousand Oaks, CA: Sage Publications.

DiLalla, L. F., \& Gottesman, I. I. (1991). Biological and genetic contributors of violence - Widom's untold tale. Psychological Bulletin, 109, 125-129.

Doumas, D., Margolin, G., \& John, R. S. (1994). The intergenerational transmission of aggression across three generations. Journal of Family Violence, 9, $157-175$.

Follette, V. M., \& Alexander, P. C. (1992). Dating violence: Current and historical correlates. Behavioral Assessment, 14, 39 - 52. 
Follingstad, D. R., Rutledge, L. L., Berg, B. J., Hause, E. S., \& Polek, D. S. (1990). The role of emotional abuse in physically abusive relationships. Journal of Family Violence, 5, 107 120.

Gardner, W., Mulvey, E. P., \& Shaw, E. C. (1995). Regression analyses of counts and rates: Poisson, overdispersed Poisson, and negative binomial models. Psychological Bulletin, $118,392-404$.

Grandin, E., \& Lupri, E. (1997). Intimate violence in Canada and the United States: A cross-national comparison. Journal of Family Violence, 12, 417-443.

Jackson, N. A. (1996). Observational experiences of intrapersonal conflict and teenage victimization: A comparative study among spouses and cohabitors. Joumal of Familv Violence, $11,191-203$.

Jacobson, N. S., Gottman, J. M., Gortner, E., Berns, S., \& Wu Shortt, J. (1996).

Psychological factors in the longitudinal course of battering: When do the couples split up? When does the abuse decrease? Violence and Victims, 11, $371-392$.

Kalmuss, D. (1984). The intergenerational transmission of marital aggression. Journal of Marriage and the Family, 46, $11-19$.

Kwong, M. J., \& Bartholomew, K. (June, 1998). A gender comparison of domestic violence in the City of Vancouver. International Society for the Study of Personal Relationships 1998 Conference, Saratoga Springs, NY.

Kwong, M. J., Bartholomew, K., \& Dutton, D. G. (1999). Gender differences in patterns of relationship violence in Alberta. Canadian Joumal of Behavioural Science, 31, 150-160.

MacEwen, K. E. (1994). Refining the intergenerational transmission hypothesis. Journal of Interpersonal Violence, $9,350-365$. 
Magdol, L., Moffitt, T. E., Caspi, A., Newman, D. L., Fagan, J., \& Silva, P. A. (1997). Gender differences in partner violence in a birth cohort of 21 -year-olds: Bridging the gap between clinical and epidemiological approaches. Journal of Consulting and Clinical Psychology, 65, 68-78.

Marshall, L. L., \& Rose, P. (1988). Family of origin violence and courtship abuse. Journal of Counseling and Development, $66,414-418$.

Mihalic, S. W., \& Elliott, D. (1997). A social learning theory model of marital violence. Joumal of Family Violence, 12, $21-47$.

Moffitt, T. E., Caspi, A., Krueger, R. F., Magdol, L., Margolin, G., Silva, P. A., \& Sydney, R. (1997). Do partners agree about abuse in their relationship? A psychometric evaluation of interpartner agreement. Psychological Assessment. 9, 47 - 56.

Morse, B. J. (1995). Beyond the Conflict Tactics Scale: Assessing gender differences in partner violence. Violence and Victims, 10, 251-272.

O’Keefe, M. (1997). Predictors of dating violence among high school students. Journal of Interpersonal Violence, $12,546-568$.

O'Leary, K. D., Malone, J., \& Tyree, A. (1994). Physical aggression in early marriage: Prerelationship and relationship effects. Journal of Consulting and Clinical Psychology, 62, 594 $-602$.

Pedhazur, E. J. (1997). Multiple regression in behavioral research: Explanation and prediction ( $3^{\text {rd }}$ ed.). Orlando: Harcourt Brace.

Schwartz, M. D. (1989). Asking the right questions: Battered wives are not all passive. Sociological Viewpoints, 5, 46-61. 
Statistics Canada (1993). The Violence Against Women Survey. The Daily, November 18, 1993. Ottawa, ON: Ministry of Industry, Science, and Technology.

Stets, J. E. \& Straus, M. A. (1990). Gender differences in reporting marital violence and its medical and psychological consequences. In M. A. Straus \& R. J. Gelles, Physical Violence in American Families: Risk Factors and Adaptations to Violence in 8,145 Families (pp. 227 244). New Brunswik, NJ: Transaction Publishing.

Straus, M. A. (1979). Measuring intrafamily conflict and violence: The Conflict Tactics (CT) Scales. Journal of Marriage and the Family, 41, 75 - 88.

Straus, M. A., \& Gelles, R. J. (1986). Society change and change in family violence from 1975 to 1985 as revealed by two national surveys. Journal of Marriage and the Family, $48, .465$ $-479$.

Straus, M. A., Gelles, R. J., \& Steinmetz, S. K. (1980). Behind Closed Doors: Violence in the American Family. Anchor Press/Doubleday, Garden City, NY.

Straus, M. A., Hamby, S. L., Boney-McCoy, S., \& Sugarman, D. B. (1996). The Revised Conflict Tactics Scales (CTS2). Journal of Family Issues, 17, 283 - 316.

Straus, M. A., \& Kantor, G. K. (1994). Corporal punishment of adolescents by parents: A risk factor in the epidemiology of depression, suicide, alcohol abuse, child abuse, and wife beating. Adolescence, $29,543-561$.

Tolman, R. (1989). The development of a measure of psychological maltreatment of women by their male partners. Violence and Victims, 4, $159-177$.

Widom, C. S. (1989). The intergenerational transmission of violence. In N. A. Weiner \& M. E. Wolfgang, Pathways to Criminal Violence, (pp. 137 - 201). Newbury Park: Sage Publications. 
Appendix A

Physical Aggression Scale

Have you ever:

1. pushed or shoved a partner? (If yes):

In the past 12 months, how often have you done this?

Has a partner ever done this? (If yes):

In the past 12 months, how often has a partner done this?

2. slapped a partner? etc.

3. thrown something at a partner that could hurt?

4. twisted a partner's arm or hair?

5. used a knife or gun on a partner?

6. punched a partner?

7. hit a partner with something that could hurt?

8. choked a partner?

9. slammed a partner against a wall?

10. beaten up a partner?

11. grabbed a partner or held a partner down in anger?

12. burned or scalded a partner on purpose?

13. kicked a partner.

14. scratched or bitten a partner during a conflict? 


\section{Appendix B}

\section{Psychological Aggression Scale}

Have you ever:

1. shouted or yelled at a partner (If yes):

In the past 12 months, how often have you done this?

Has a partner ever done this? (If yes):

In the past 12 months, how often has a partner done this?

2. ignored, shut out or given a partner the silent treatment?

3. called a partner hurtful names?

4. criticized or put down a partner in front of others?

5. limited a partner's contact with others such as family or friends?

6. controlled a partner's behaviour or activities in any way?

7. acted jealous or suspicious of a partner's other relationships?

8. insulted or sworn at a partner?

9. intentionally destroyed something belonging to a partner?

10. threatened to hit, hurt, or throw something at a partner?

11. thrown, smashed, hit, or kicked something in a partner's presence?

12. threatened to hurt a partner if they left the relationship?

13. threatened to hurt yourself if a partner left the relationship? 